\begin{tabular}{|c|c|c|}
\hline Beitr. Ent. & Keltern & ISSN 0005-805X \\
\hline $\mathbf{6 0}(2010) 1$ & S. $111-123$ & 31.07 .2010 \\
\hline
\end{tabular}

\title{
Contribution to the knowledge of the Xantholini from China. XV. New species collected by Michael Schülke in Zhejiang and Yunnan
}

\author{
(Coleoptera, Staphylinidae) ${ }^{1}$
}

With 5 figures

Arnaldo Bordoni

Summary

The following species are described from Yunnan: Mahavana gaoligong n. sp., Mahavana daliana n. sp., Yunna fungicola n. sp., Atopolinus uncinatus n. sp., Atopolinus inusualis n. sp., Atopolinus subtropicalis n. sp., and Atopolinus schuelkei n. sp. Emathidis humerosa (Bernhauer) is new for Zhejiang and Megalinus anhuensis (BoRDonI) is new for Yunnan.

\section{Zusammenfassung}

Mahavana gaoligong n. sp., Mahavana daliana n. sp., Yunna fungicola n. sp., Atopolinus uncinatus n. sp., Atopolinus inusualis n. sp., Atopolinus subtropicalis n. sp., und Atopolinus schuelkei n. sp. werden als neue Arten aus Yunnan, China beschrieben. Weiterhin werden Emathidis humerosa (Bernhauer) erstmals in Zhejiang und Megalinus anhuensis (BordonI) erstmals in Yunnan nachgewiesen.

\section{Introduction}

Michael Schülke of Berlin sent me in study the Xantholinini collected in June of 2007, with some colleagues, in Zhejiang and especially in Yunnan. The examined area of Yunnan, include the Dali Bai, Nujiang Lisu, and in particular the Baoshan Prefectures. This last county, at the borderline to Myanmar, comprise the Gaoligong Shan, near Tengchong, that is a very interesting mountainous and subtropical district, with a valuable biodiversity. I add few specimens preserved in the collections of A. Pütz, Eisenhüttenstadt and Y. Watanabe, Tokyo.

The scale bar refers to all the figures in the tables, except those relating to the male genital segments (figs 9, 12, 17, 24, 29) that are helved compared to other, and those relating to the head (figs 1 and 6) whose dimensions are given in the text.

Current knowledge of Xantholinini from Zhejiang and Yunnan is profoundly different. In fact there are only 8 known species from the first province while 37 species are known from the second region. This difference is due to the fact that Yunnan has been the subject of many entomological expeditions in recent years, much more so than in Zhejiang.

\footnotetext{
${ }^{1} 195$ contribution to the knowledge of the Staphylinidae.
} 
Apart from some ancient descriptions, most of the species was described by the writer over the past 10 years. As for Zhejiang there are known species belonging to 7 genera while the Yunnan there are species belonging to 18 genera. Nine genera and 26 species have been described by the writer, apart the species described in this contribution. Genera most representative or most interesting for morphological characters in Yunnan are Yunnella Bordoni, 2002; Mahavana Bordoni, 2002; Metosina Bordoni, 2002; Megalinus Mulsant \& Rey, 1877, Medhiama Bordoni, 2002, and Atopolinus Coiffait, 1982.

\section{Acronims}

cB coll. Bordoni, Firenze

cP coll. Pütz, Eisenhüttenstadt

cS coll. Schülke, Berlin

$\mathrm{cW} \quad$ coll. Watanabe, Tokyo

\section{Mabavana gaoligong n. sp.}

\section{Material examined:}

Holotype $\sigma^{*}$ : Yunnan, Baoshan Pref., Gaoligong Shan, 29 km ESE Tengchong, 2350 m, 24.55N, 98.45E, M. Schülke 1.VI.2007 (cS); paratypes: same data, 2 ㅇ ㅇ (cS), 2 o $^{\star{ }^{*}}(\mathrm{cB})$; same data, A. Pütz 1.Vi.2007, $10^{*}$ (cP).

\section{Description:}

Body $4 \mathrm{~mm}$ long; length from the anterior margin of the head to the posterior margin of elytra: $2,2 \mathrm{~mm}$. Head black brown; antennae, legs, pronotum, elytra and abdomen yellow brown. Head $0,6 \mathrm{~mm}$ long (fig. 1) dilated anteriorly and restricted backwards. Antennae as in fig. 2. Eyes evident and well protruding. Similar to $M$. anothera Bordoni but shorter, with head smaller, pronotum narrower and proportionally longer, with more evident and numerous punctures; elytra proportionally narrower and shorter, with subrectilinear sides.

Tergite and sternite of the male genital segment as in figs 3-4. Aedeagaus subcircular (fig. 5), with arcuated parameres; internal sac with a circle of big subtriangular spines.

\section{Etymology:}

It take its name from the type locality of Gaoligong Shan.

\section{Bionomy:}

"Deciduous forest, in litter, wood and fungi" (from the label).

\section{Distribution:}

I know this species only from the Gaoligong Shan.

\section{Notes:}

This species is related to $M$. anothera (Bordoni, 2002) from North Thailand, but differs by the structure of the aedeagus and its internal sac. 

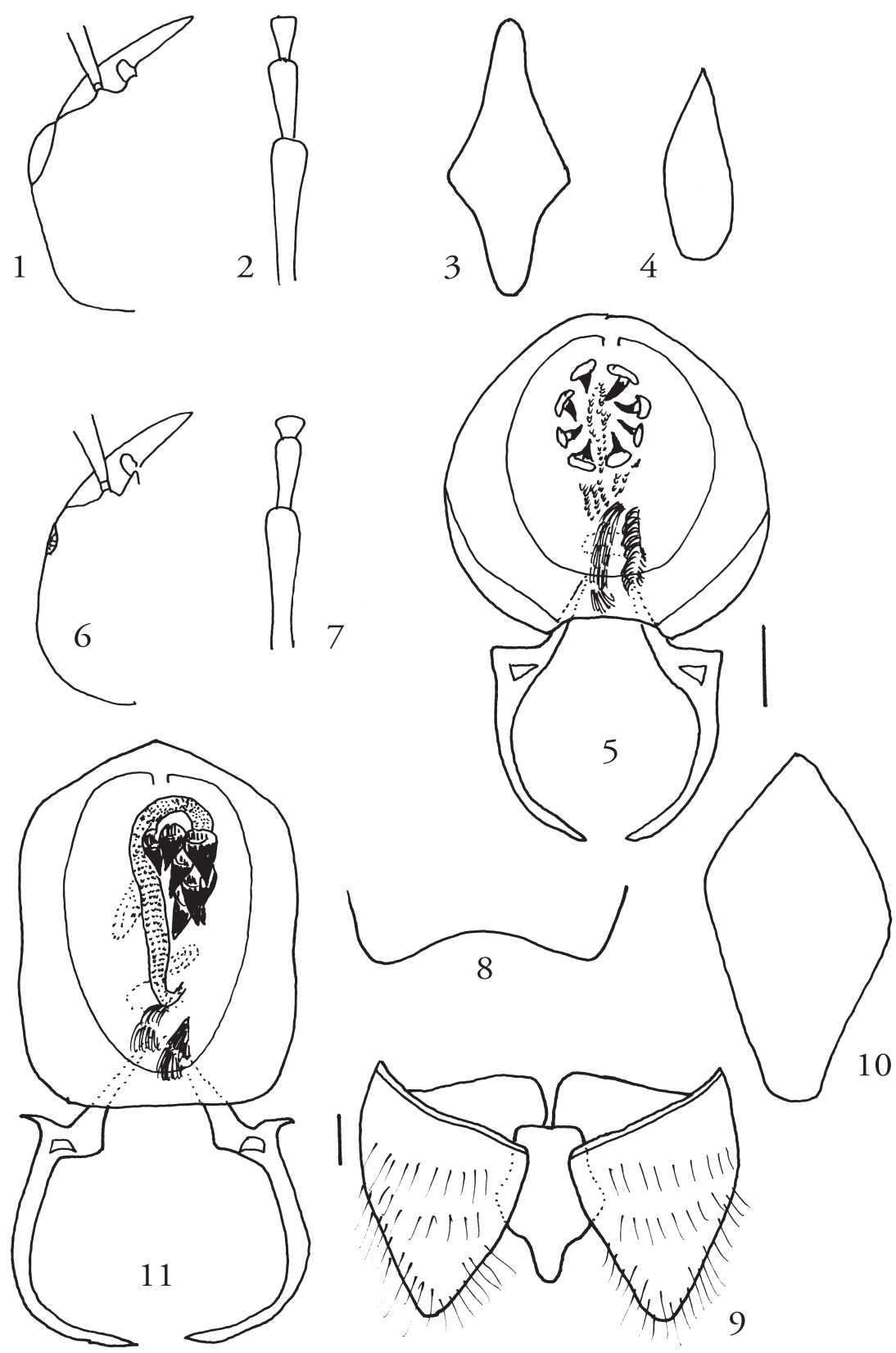

Figs 1-11: Mahavana gaoligong n. sp.: 1 head (right half omitted); 2 antenna; 3 tergite of the male genital segment; 4 sternite of the same; 5 aedeagus. Mahavana daliana n. sp.: 6 head (right half omitted); 7 antenna; $86^{\circ}$ visible sternite; 9 male genital segment; 10 sternite of the same; 11 aedeagus (bar scale: $0,1 \mathrm{~mm}$ ). 


\section{Mabavana daliana n. sp.}

Material examined:

Holotype o : Yunnan, Dali Bai Aut. Pref., Diancang Shan, W Dali, 25.41N, 100.06E, 2860 m, M. Schülke 28.V.2007 (cS); paratypes: same data, 1 ㅇ (cS), 1 ㅇ (cB); Yunnan, Baihualing, Gaoligongshan Mts., 2290 m, Baoshan Xian, K. Ishii at al. 16.X.1996, 1 \% (cW).

\section{Description:}

Body 4,5 mm long; length from the anterior margin of the head to the posterior margin of elytra: 2,3 mm. Sub anophthalmous and brachypterous species. Yellow reddish, shiny. Head 0,7 mm long (fig. 6) not dilated anteriorly, sub rectangular with rounded sides. Eyes very small and flat, reduced to a few ommatidia. Head with numerous points on both sides of a median strip. Antennae as in fig. 7. Pronotum longer than head, dilated anteriorly, with anterior angles obsolete, almost not sinuate sides. Surface with dorsal series of 11-12 large points and lateral series of 5-6 points. Elytra short, shorter and feebly larger than pronotum, with humera slightly and strictly rounded. Surface with numerous series of very fine points. Abdomen with irregular polygonal micro reticulation and fine punctation.

Sixth visible male sternite with concave posterior margin (fig. 8). Male genital segment as in fig. 9, with peculiar tergite and sternite as in fig. 10. Aedeagus (fig. 11) sub rectangular, with very long parameres; internal sac long e narrow, covered by minute scales and with 5-6 big and large spines.

\section{Etymology:}

It take its name from the locality of Dali.

\section{Bionomy:}

"Pine forest, in litter, moss and dead wood" (from the label).

\section{Distribution:}

I know this species from the type localitys.

\section{Notes:}

Very closely related to M. watanabei Bordoni (2009) from Gaoligong Shan but differing by the thick punctation on the head, by the pronotum not narrower than head, with different punctation (dorsal and lateral series of points rather than 5-6 rows of points on both sides of a median strip), by the structure of the internal sac of the aedeagus.

The genus was known for a little number of species distributed in the Indochinese Peninsula and Yunnan and from few specimens. The study of the material listed in this contribution allowed me to enlarge the knowledge of Mahavana and to observe that the genus consists, almost in Yunnan, of two groups of species, one with big eyes and one sub anophthalmous.

\section{Emathidis humerosa (BERNHAUER, 1934)}

Material examined:

Zhejiang, West Tianmu Shan, pass $25 \mathrm{~km}$ NNW Linan, 620-820 m, 30.25N, 119.35E, W. Wrase 16.VI.2007, 3 exx. (cS), 2 exx. (cB); Tianmu Shan N. P., way to peak of immortals, 30.20N, 119.23E, 1100-1200 m, M. Schülke 15.VI.2007,1 ex. (cB); same data, A. Pütz 15.VI.2007, 1 exx. (cP) 1 ơ (cB); same 
data, path to peek of immortals, ("Blind alley"), 1100-1200 m, 30.20N, 119.25E, W. Wrase 15.VI.2007, $1 \sigma^{\top}$ (cB); Hangzhou Pref., Tianmu Shan, 40 km WNW Linan, 30.20N, 119.18E, W. Wrase 17.VI.2007, 1 ex. (cB).

\section{Bionomy:}

"Primary mixted forest, in litter and moss; creek valley with bamboo and mixed forest, in litter; rock edges, in litter" (from the label).

\section{Notes:}

Described as Xantholinus, this species was attribuited to the genus Cibyra Bordoni, 2002 (Bordoni, 2003), but this name was employed by WALKER (1856) for a genus of Lepidoptera. Cibyra was recently replaced by Emathidis (Bordoni, 2007). The only specimen (male) still now known for this species is preserved in the Field Musem of Natural History of Chicago. The genus include only two species: dilucida Bordoni, 2002 from South Vietnam and humerosa (BERnhauer). It is evident that the current knowledge on the distribution of the genus is totally inadequate. Emathidis humerosa is new for Zhejiang.

\section{Yunna rubens BoRDONI, 2002}

\section{Material examined:}

Yunnan, Nujiang Lisu Aut. Pref., Nushan, 7 km NNW Coajian, 2420, 25.43N, 99.07E, W. Wrase 11.VI.2007, 9 exx. (cS), 4 exx. (cB).

\section{Bionomy:}

"Secondary pine forest with shrubs, in litter and moss" (from the label).

\section{Notes:}

This species is known from Yunnan, Shaanxi, Sichuan (Bordoni, 2002, 2003) and Guangxi (BORDONI, 2007).

\section{Yunna fungicola n. sp.}

\section{Material examined:}

Holotype ơ: Yunnan, Baoshan Pref., Gaoligong Shan, E pass $36 \mathrm{~km}$ SE Tengchong, $2200 \mathrm{~m}, 24.49 \mathrm{~N}$, 98.46E, M. Schülke 31.V.2007 (cS); paratypes: same data, 1 ㅇ (cS), 1 ơ , 2 ㅇ 우 (cB).

\section{Description:}

Body $6 \mathrm{~mm}$ long; length from the antrerior margin of the head to the posterior margin of elytra: 3,5 mm. Forebody black, abdomen brown, antennae brown black, legs testaceous. Head sub rectangular, with sub parallel sides and posterior angles strictly rounded. Eyes moderately large and protruding. Surface of the head shiny, with two series of three points between the eyes and with punctation more or less large and scattered. Pronotum longer and narrower than head, with slightly oblique anterior margins and largely rounded anterior angles. Surface shiny, with dorsal series of 9-10 irregular points and lateral series of 5-6 irregular points. Elytra large, longer and larger than pronotum, sub rectangular, with sub parallel sides and evident humera. Surface irregular but shiny, with some series of very fine points. Abdomen with fine and more or less polygonal microreticulation and fine punctation. 
Male genital segment as in fig. 12, with sternite sub quadrate (fig. 13) and partially membranous. Aedeagus (fig. 14) very small (0,85 mm long), diaphanous, with symmetrival and peculiar parameres, internal sac moderately long and narrow, transparent, with scattered minute scales.

\section{Etymology:}

It take its name from the Latin fungicolus-a- um (fungiculous).

\section{Bionomy:}

"Deciduous forest, in litter, wood and fungi" (from the label).

\section{Distribution:}

I know this species only from the type locality.

\section{Notes:}

The genus Yunna Bordoni, 2002 seems to live only in China and was represented until now by two species ( $Y$. micophora Bordoni, 2002 from Yunnan and the cited $Y$. rubens). The new species is similar to these but larger and with different aedeagus.

\section{Megalinus anbuensis (BORDONI, 2007)}

\section{Material examined:}

Yunnan, Nujiang Lisu Aut. Pref., Gaoligong Shan, side valley 18 km NW Liuku, 2590 m, 25.58N, 98.42E, W. Wrase 9-10.VI.2007, 1 o $^{\star}$ (cS).

\section{Bionomy:}

"Devasted primary forest, in litter" (from the label).

\section{Notes:}

This species was known from Hubei and Anhui. It is new for Yunnan.

\section{Atopolinus ovaliceps (SCHEERPELTZ, 1965)}

\section{Material examined:}

Yunnan, Baooshan Pref., mount. Range 25 km S Tengchong, 1900 m, 24.48N, 98.32E, W. Wrase 2.VI.2007, 1 ㅇ (cS); 22 km S Tengchong, 1750 m, 24.49N, 98.29E, M. Schülke 2.VI.2007, 1 ơ (cB).

\section{Bionomy:}

"Devastated primary foret, in litter; secondary forest, in litter and dead wood" (from the label).

\section{Notes:}

This species was known from Bhutan, North Myanmar, North Thailand, Malaysia, Yunnan, Guizhou, Huaxi (Bordoni, 2002). 

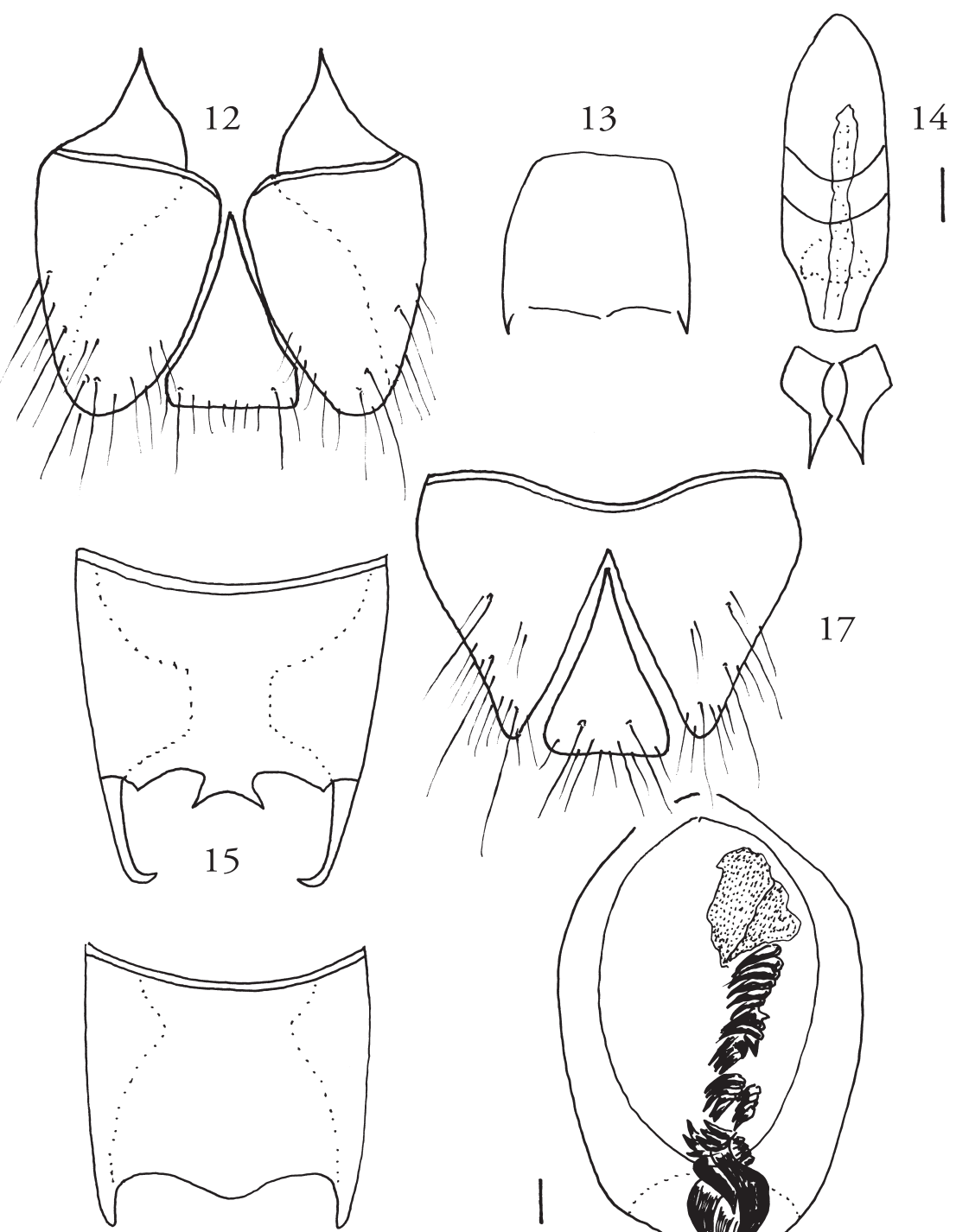

16

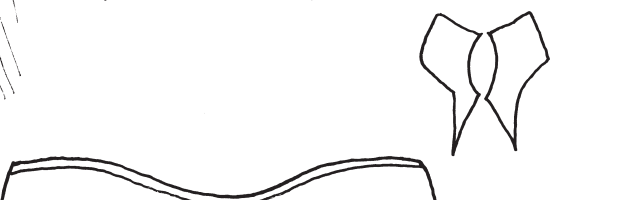

Figs 12-18: Yunna fungicola n. sp.: 12 male genital segment; 13 sternite of the same; 14 aedeagus. Atopolinus uncinatus n. sp.: $156^{\circ}$ visible tergite; $166^{\circ}$ visible sternite; 17 male genital segment; 18 aedeagus (bar scale: $0,1 \mathrm{~mm})$. 


\section{Atopolinus uncinatus n. sp.}

Material examined:

Holotype o : Yunnan, Dali Bai Aut. Pref., Wuliang Shan, 9 km SW Weishan, 2450-2500 m, 25.10N, 100.14E, M. Schülke 13.VI.2007 (cS); paratypes: same data, 1 o $^{\star}, 6$ 우 우 (cS), 2 o $^{\star} o^{\star}, 2$ 우 우 (cB); same data, A. Pütz leg. 13.VI.2007, $1 \sigma^{\star}, 2$ 우 ㅇ (cP); $2 \sigma^{\star} \sigma^{\star}$ (one abdomen lost), 1 ㅇ (cB); same data, W. Wrase 13.VI.2007, 1 \% (cS).

\section{Description:}

Body $7 \mathrm{~mm}$ long; length from the antrerior margin of the head to the posterior margin of elytra: $3,5 \mathrm{~mm}$. Brachypterous. Body slender, reddish brown with light humera; antennae and legs yellow-brown. Head ovoid, with largely rounded posterior angles. Eyes very small and almost flat. Surface of the head shiny, with very fine and scattered punctation. Pronotum shiny, slightly longer and narrower than head, with largely rounded anterior angles, sides almost rectlinear, with dorsal series of 8-9 points and lateral series of 6-7 irregular points; other points near the sides of the pronotum. Elytra shorter and scarcely larger than pronotum, with obsolete humera. Surface shiny, feebly rugose, with numerous series of fine and thick punctation. Abdomen with very fine and superficial transversal micro striature and fine punctation.

Sixth visible tergite with posterior margin very peculiar, as in fig. 15 and $6^{\circ}$ visible sternite as in fig. 16. Male genital segment symmetrical (fig. 17), with connected basal portion of the pleurae, and sternite as in fig. Aedeagus (fig. 18) with pseudoparameres partially membranous; internal sac with numerous spinules and three big distal spines.

\section{Etymology:}

It takes its name from the Latin uncinatus- a- um (hooked) (see the $6^{\circ}$ visible tergite).

\section{Bionomy:}

"Forest with oaks and pines, in litter" (from the label).

\section{Distribution:}

It is known to me only from the type locality.

\section{Notes:}

This new species is related to A. subnigroaeneus (Corffait, 1982) from Nepal and West Bengala (Bordoni, 2002) by the general shape of the distal part of the abdomen in dorsal view, but differs by the structure of the $6^{\circ}$ visible abdominal segment, pseudoparameres and internal sac of the aedeagus.

\section{Atopolinus inusualis n. sp.}

\section{Material examined:}

Holotype ơ: Yunnan, Dali Bai Aut. Pref., mnt range N Er Hai, $42 \mathrm{~km} \mathrm{~N}$ Dali, 2500-2550 m, 26.04N, 100.09E, M. Schülke 16.VI.2007 (cS); paratype: same data, 5 우 우 (cS), 1 ơ , 3 우 우 (cB).

\section{Description:}

Body $8 \mathrm{~mm}$ long; length from the antrerior margin of the head to the posterior margin of elytra: $4 \mathrm{~mm}$. Reddish brown, with antennae and legs testaceous. Head ovoid, with largely rounded 
posterior angles. Eyes small and slightly protruding. Surface of the head shiny, with two series of three large points between the eyes, and with fine and scattered points, especially on the sides. Pronotum sub rectangular, not dilated anteriorly, longer than head, as large as head, with rounded anterior angles. Surface shiny, with dorsal series of 7-8 points and lateral series of 4 ponts, all similar that those of the head. Elytra short, shorter than pronotum, sub rectangular, with evident humera. Surface shiny, with numerous series of large points. Abdomen with fine transversal microstriation and fine punctation.

Tergite and sternite of the male genital segment as in figs 20-21. Aedeagus (fig. 22) large (2,2 mm long), sub ovoid, with asymmetrical sub triangular pseudoparameres, partially membranous; internal sac large and long, ribbon-like, covered by evident fine spinules and with some long transversal spines on the distal portion.

\section{Etymology:}

It take its name by the Latin inusualis- $e$ (unusual) (see the shape of the internal sac of the aedeagus).

\section{Bionomy:}

"Oaks forest, in litter" (from the label).
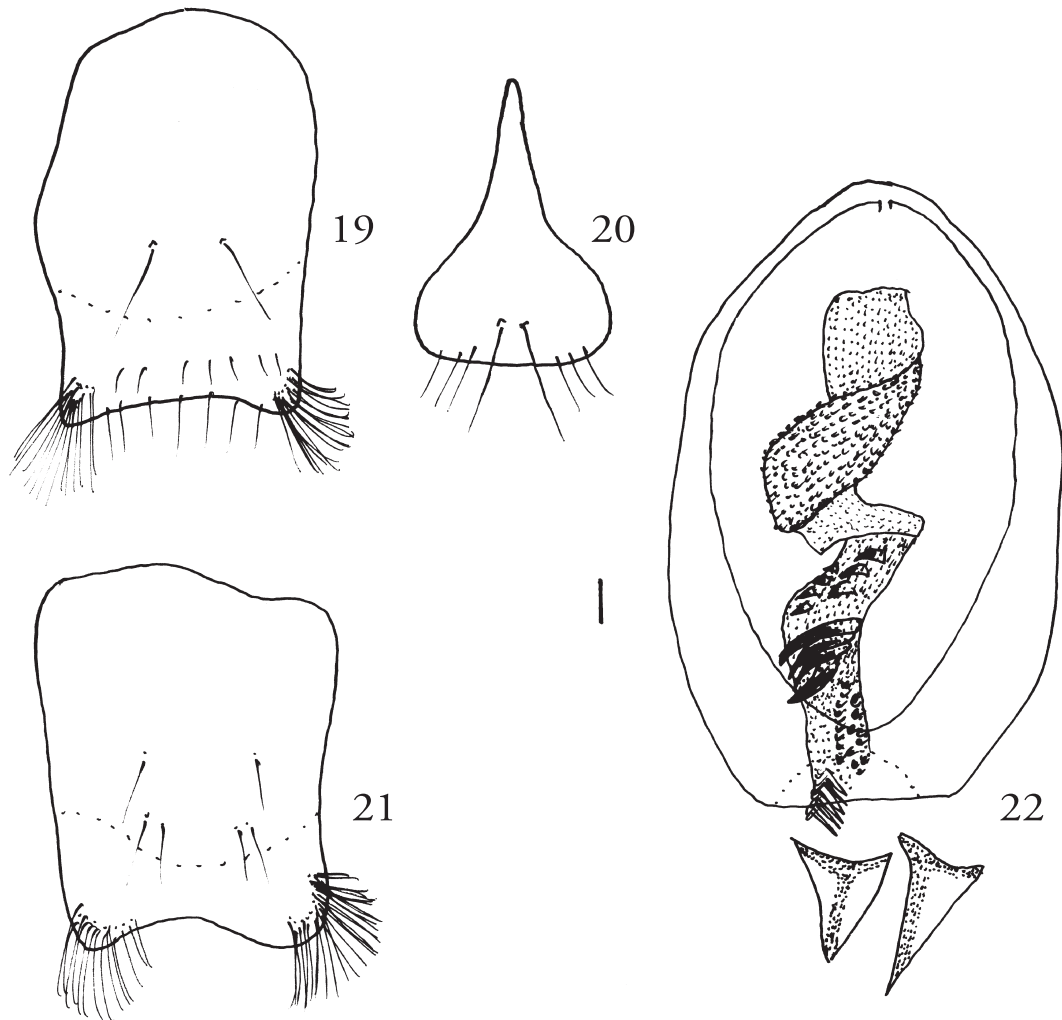

Figs 19-22: Atopolinus uncinatus n. sp.: 19 sternite of male genital segment. Atopolinus inusualis n. sp.: 20 tergite of male genital segment. 21 sternite of the same; 22 aedeagus (bar scale: $0,1 \mathrm{~mm}$ ). 


\section{Distribution:}

It is known to me only from the type locality.

Notes:

This species differs from the congeneric taxa by the shape of the internal sac of the aedeagus.

\section{Atopolinus subtropicalis n. sp.}

\section{Material examined:}

Holotype $0^{\star}$ : Yunnan, Nujiang Lisu Aut. Pref., Gaoligong Shan, 9 km W Gongshan, 2660 m, 27.45N, 98.34E, W. Wrase 7.VI.2007 (cS); paratype: same data, 1 ㅇ (cB).

\section{Description:}

Body $9,5 \mathrm{~mm}$ long; length from the antrerior margin of the head to the posterior margin of elytra: $5 \mathrm{~mm}$. Large and shiny species. Black with antennae and legs brown. Pubescence of the body yellow light. Head big, long, dilated backwards, with strictly rounded posterior angles. Eyes small and slightly protruding. Surface of the head with two series of three points between the eyes and with scattered, deep puncturation. Pronotum narrow, longer and narrower than the head, with oblique anterior margins and largely rounded anterior angles, with dorsal series of 11-12 irregular points and lateral sieries of 9-10 irregular points. Elytra sub rectangular, as long as the pronotum, larger than the pronotum, with evident humera, with numerous series of fine puncturation. Abdomen with fine transversal micro striation and fine puncturation.

Sixth visible tergite as in fig. 23 , with characteristic posterior margin; $6^{\circ}$ visible sternite with the posterior margin feebly concave. Male genital segment (fig. 24) asymmetric, with sternite as in fig. 25 . Aedeagus (fig. 26$)$ very big $(2,33 \mathrm{~mm}$ long), with minute and asymmetrical pseudoparameres; internal sac with numerous large spines.

\section{Etymology:}

It take its name from the subtropical forest of the type locality.

\section{Bionomy:}

"Under stones along pass road" (from the label).

\section{Distribution:}

It is known to me only from the type locality.

\section{Notes:}

This species is peculiar by the large dimension, the black colouration and the structures of the internal sac of the aedeagus.

\section{Atopolinus schuelkei n. sp.}

Material examined:

Holotype $0^{*}$ : Yunnan, Gaoligong Shan, 29 km ESE Tengchong, 2350 m, 24.55N, 98.45E, W. Wrase 1.VI.2007 (cS). 


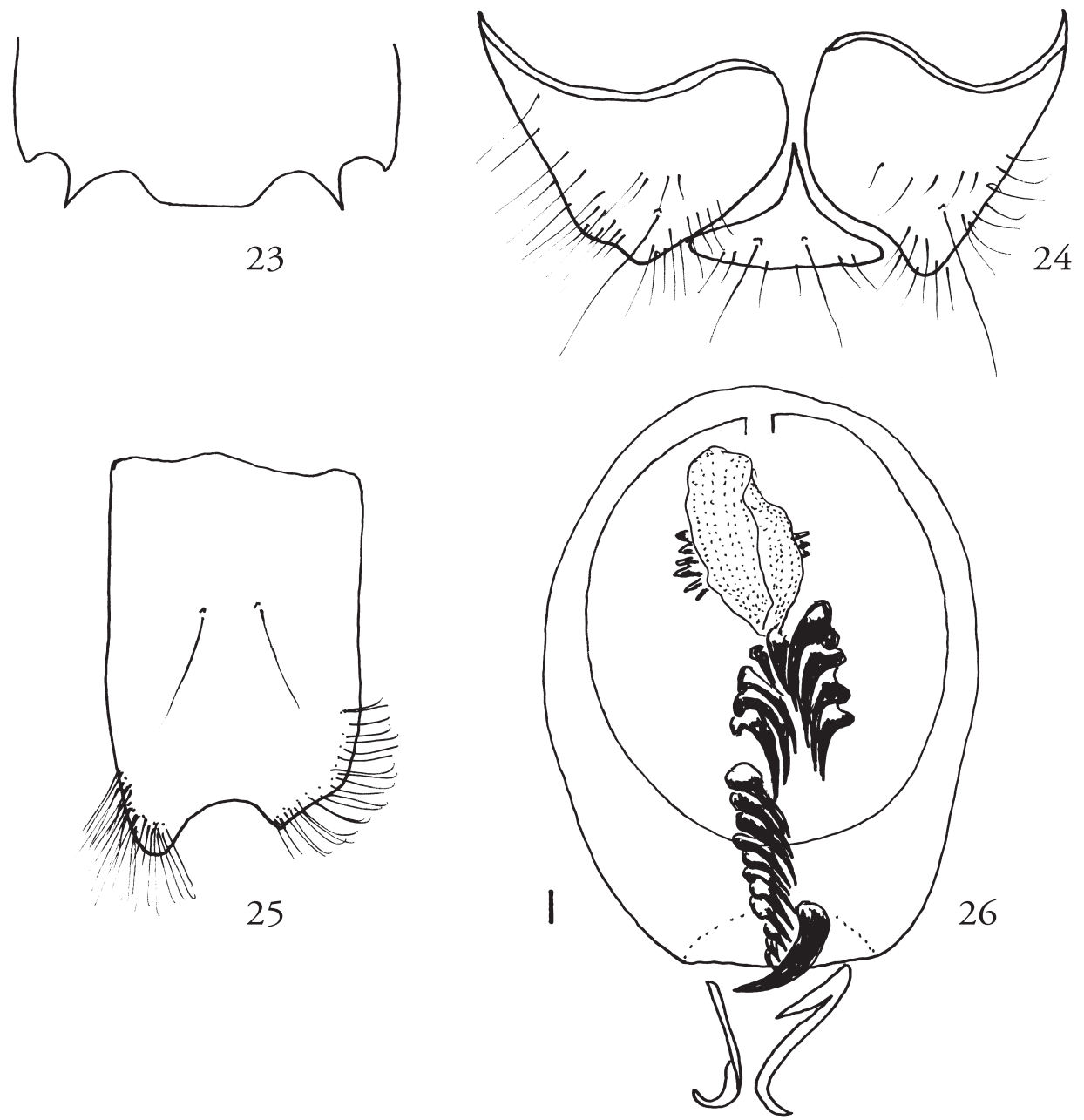

Figs 23-26: Atopolinus subtropicalis n. sp.: $236^{\circ}$ visible tergite; 24 male genital segment. 25 sternite of the same; 26 aedeagus (bar scale: $0,1 \mathrm{~mm}$ ).

\section{Description:}

Body $6,5 \mathrm{~mm}$ long; length from the antrerior margin of the head to the posterior margin of elytra: 4,5 mm. Head black, pronotum, elytra and abdomen reddish brown with humera yellow red; antennae testaceous; legs yellowish. Body shiny. Head ovoid, dilated backwards, with largely rounded posterior angles. Eyes moderately large and protruding. Surface of the head with two series of three points between the eyes and with very scattered puncturation. Pronotum longer and narrower than the head, with oblique anterior margins and largely rounded anterior angles. Surface with dorsal series of 6 large and scattered points and lateral series of 4 small points. Elytra very large, longer and larger than pronotum, dilated backwards, with evident humera. Surface with three series of large points near the suture and one median series; other points near the epipleural sides. Abdomen with fine transversal micro striation and fine puncturation. 

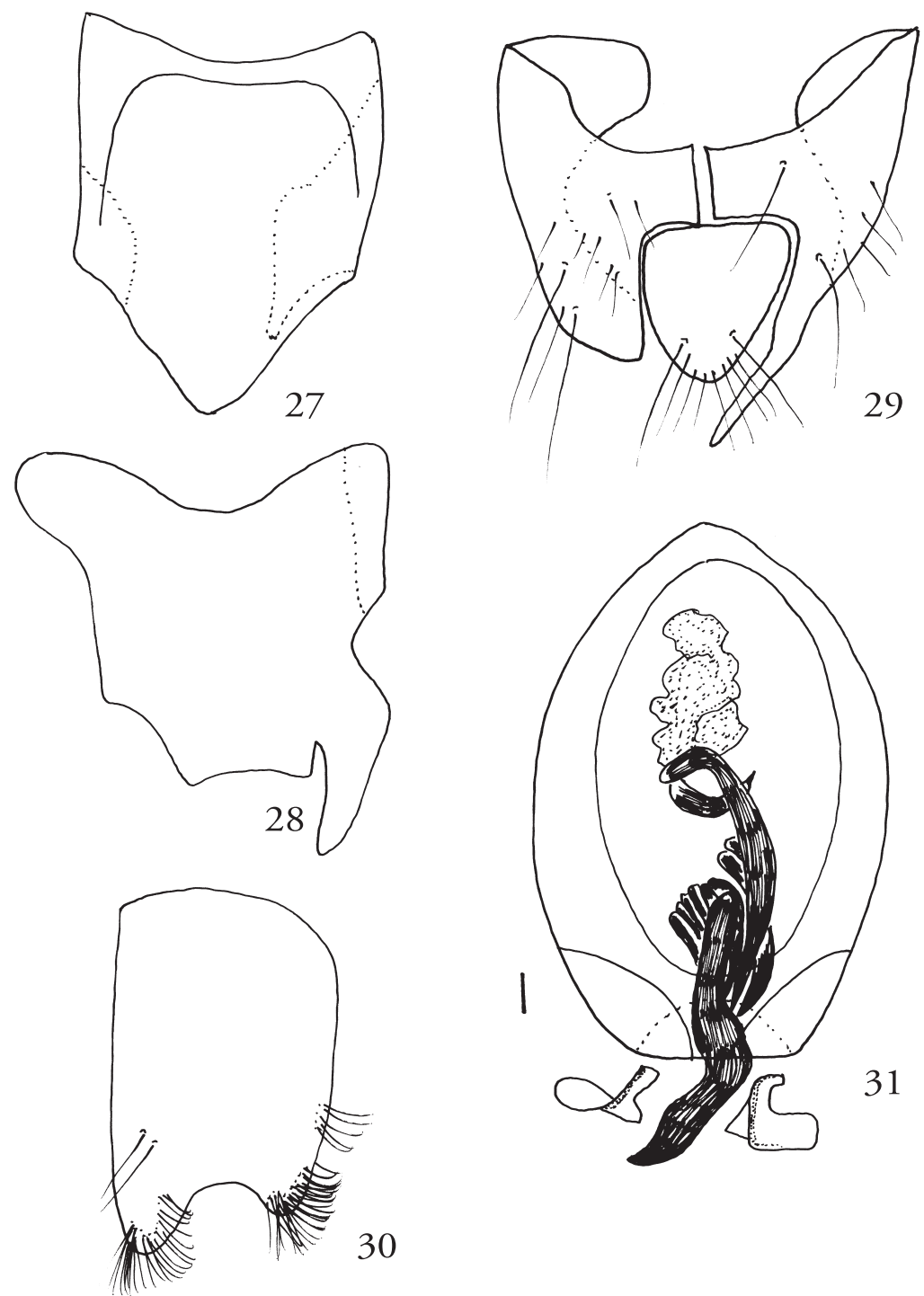

Figs 27-31: Atopolinus schuelkei n. sp.: $276^{\circ}$ visible tergite; $286^{\circ}$ visible sternite; 29 male genital segment; 30 sternite of the same; 31 aedeagus (bar scale: $0,1 \mathrm{~mm}$ ).

Sixth visible tergite and sternite of peculiar shape (figs 27-28). Male genital segment asymmetric, with the right pleura, in dorsal view, provided by a long distal lobule (fig. 29); sternite as in fig. 30. Aedeagus (fig. 31) large (1,65 mm long), with short pseudoparameres; internal sac with two big and long spines and other less large spines in the median portion.

\section{Etymology:}

Dedicated to Michael Schülke, well known specialist in Tachyporinae. 


\section{Bionomy:}

"Devastated decidous forest with clearings ans shrubs, in litter and wood" (from the label).

\section{Distribution:}

It is known to me only from the type locality.

\section{Notes:}

This species is closely related to $A$. asymetricus (CoIffaIt, 1976) from Nepal by the peculiar structure of the male genital segment, but differs by the shape of the $6^{\circ}$ visible tergite and sternite and by the aedeagus.

\section{Acknowledgements}

I wish to thank heartly the colleagues Michael Schülke, Berlin, Andreas Pütz, Eisenhüttenstadt and Y. Watanabe, Tokyo by sending me material, permitted the achievement of this contribution, and John Nunn, Dunedin for the help in the English version of this paper.

\section{References}

Bordoni, A. 2002: Xantholinini della Regione Orientale (Coleoptera: Staphylinidae). Classificazione, filogenesi e revisione tassonomica. - Monografie del Museo regionale di Scienze naturali, Torino 33: 998 pp.

Bordoni, A. 2003: Contributo alla conoscenza degli Xantholinini della Cina. II. (Coleoptera, Staphylinidae). - Fragmenta entomologica, Roma 34 (2): 255-292.

Bordoni, A. 2003a: Contributo alla conoscenza degli Xantholinini della Cina. IV. Un nuovo genere e nuove specie raccolti da Michael Schülke nella Shaanxi e nel Sichuan (Coleoptera, Staphylinidae). - Beiträge zur Entomologie 53 (2): 253-275.

Bordoni, A. 2003: Contributo alla conoscenza degli Xantholinini della Cina. III. Due nuove specie dello Guangxi (Coleoptera, Staphylinidae). - Animma. x 2: 11-15.

Bordoni, A. 2007: Notes on some Western Palaearctic Xantholinini (Coleoptera, Staphylinidae). - Zootaxa 1431: 65-68.

Bordoni, A. 2009: New data for the knowledge of the Xantholinini (Coleoptera, Staphylinidae) from China. XII. Species preserved in the National Museum of Nature and Science, Tokyo. - Japanese Journal of systematic Entomology 15 (1): 267-275.

WALKER, F. 1856: List of the specimens of lepidopterous insects in the collection of the British Museum. Part VII. Lepidoptera Heteroptera. - E. Newman, London, pp. 1509-1808.

\section{Author's address:}

Dr. Arnaldo Bordoni

clo Museo Zoologico "La Specola"

Sezione del Museo di Storia Naturale dell'Università di Firenze

via Romana 17

50125 Firenze

Italy

e-mail: arnaldo.bordoni@libero.it
Subject editor:

Dr. L. ZerChe 